\title{
Power of Ambient Tempurature on the Performance of ihe Semiconductor Laser
}

\author{
J.S. Ashwin, N. Manoharan
}

Department of Electrical and Electronics Engineering (Marine), AMET University, Chennai, India

\begin{tabular}{l}
\hline Article Info \\
\hline Article history: \\
Received Nov 30, 2017 \\
Revised Feb 2, 2018 \\
Accepted Feb 19, 2018 \\
\hline
\end{tabular}

\section{Keywords:}

Ambient temperature ANSYS

Semiconductor laser Thermal properties
Copyright (C) 2018 Institute of Advanced Engineering and Science. All rights reserved.

\section{Corresponding Author:}

\section{J.S. Ashwin,}

Department of Electrical and Electronics Engineering (Marine),

AMET University, Chennai, India.

\section{INTRODUCTION}

A semiconductor (Laser Diode, LD) laser is the best and most reasonable prospect among class of lasers; the fundamental guideline is the high productivity of electron-photon transformation. In any case, because of the nearness of non-radiative recombination misfortune, free transporter assimilation misfortune components to outside differential quantum proficiency can just achieve $20 \%-30 \%$, which implies that a significant piece of the infused electric influence will be changed over to warm.As the temperature rises, the laser limit current would likewise builds, bringing about the diminished yield control, and in addition the moved emanation wavelength, this would prompt a flimsy mode, expanding inward imperfections truly, and influence the life of the gadget, and along these lines it has made incredible troubles the application.

\section{BACKGROUND}

Firstly analyzed overall thermal characteristics, in particular the impact of temperature on the semiconductor laser execution and imperative parameters to do a point by point examination to distinguish the effect of the laser chip temperature of the limit current, the optical yield control laser execution [1]-[2]. Also, utilizing ANSYS limited component examination recreation programming to reenact the impact of encompassing temperature change on a solitary chip interior temperature of the semiconductor laser [3]-[4], and locate the comparing relationship influence the connection between surrounding temperature and the temperature inside the chip. Last consequences of natural temperature on the execution of the semiconductor laser by contact. The synthesis of the Zns at the low temperature is explained in the Low temperature method for synthesis of $\mathrm{ZnS}$ quantum dots and its luminescence characterization studies [5]. 


\subsection{The Problem}

The characteristics of a laser diode are highly dependent on the temperature of the laser chip. Thus, the effect of temperature on the network performance of uncooled semiconductor laser diode are studied by simulating its equivalent electrical circuit, developed from the rate equations that governing optical components directly into an electrical simulation framework.

\subsection{The Proposed Solution}

Temperature on the execution parameters of laser limit current are exceptionally touchy, little temperature changes can significantly influence the edge current information. Because of hot transporter spillage, inner misfortune and different reasons, as the temperature rises, the edge current will rise [6]. The studies of the starch capped Znse is explained in the Low temperature method for synthesis of starch-capped ZnSe nanoparticles and its characterization studies [7]-[8].

The higher the temperature attributes, the surrounding temperature of the laser will be littler, the steadiness of the laser will be better. In the event that to wind up noticeably endlessly huge, then the edge current won't be influenced by temperature. In a few times with the rising temperature inside, the semiconductor bearer assimilation misfortune will ascend, and also the quantity of transporters, whereas the outer differential quantum efficiency is reduced [9].

\section{RESULTS AND DISCUSSIONS}

The Figure 1-3 portrays the scope of surrounding temperature from $265 \mathrm{~K}$ to $335 \mathrm{~K}$ (about less 10 degrees to 60 degrees), the temperature of the laser dynamic layer change outline, different conditions, considering just laser warm sink and air warm, gotten from the $267 \mathrm{~K}$ chip temperature to $319 \mathrm{~K}$ (about less 6 degrees to 46 degrees).

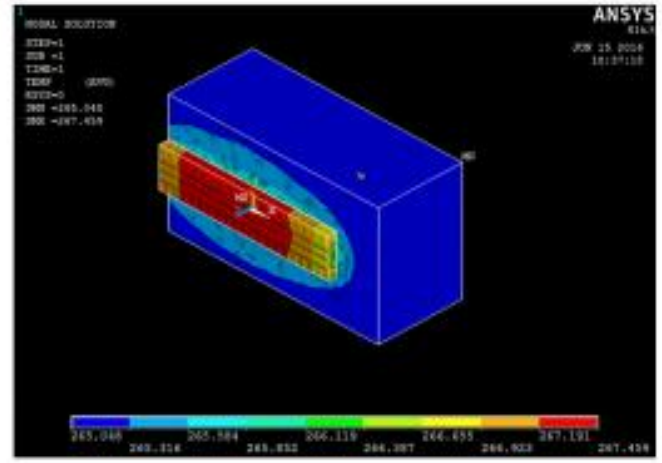

Figure 1. Ambient temperature is set at $265 \mathrm{~K}$ thermal contours lasers

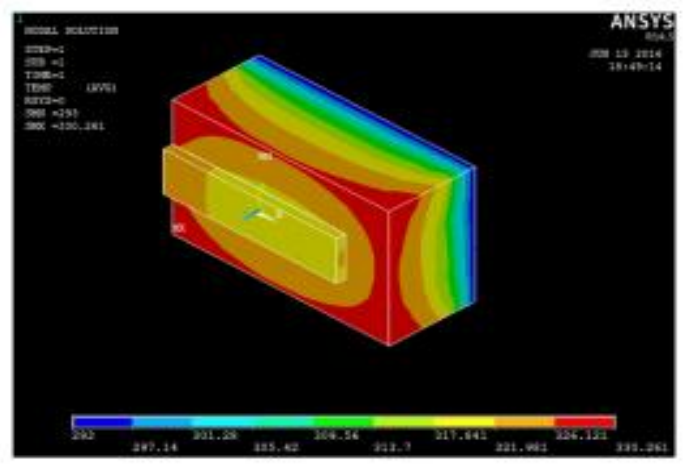

Figure 3. Ambient temperature is set at $335 \mathrm{~K}$ thermal contours lasers

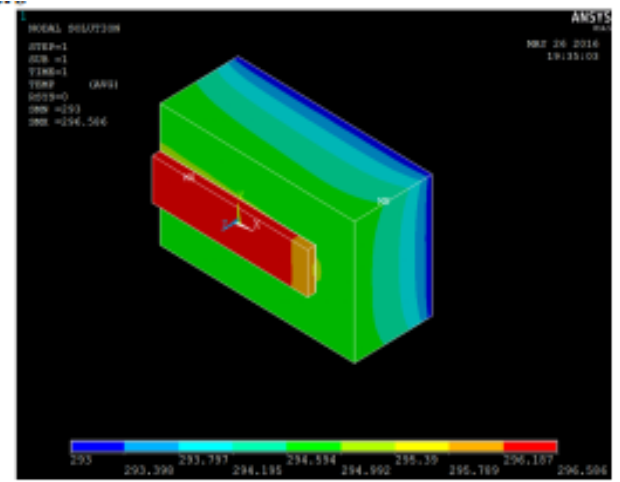

Figure 2. Ambient temperature is set at $295 \mathrm{~K}$ thermal contours lasers

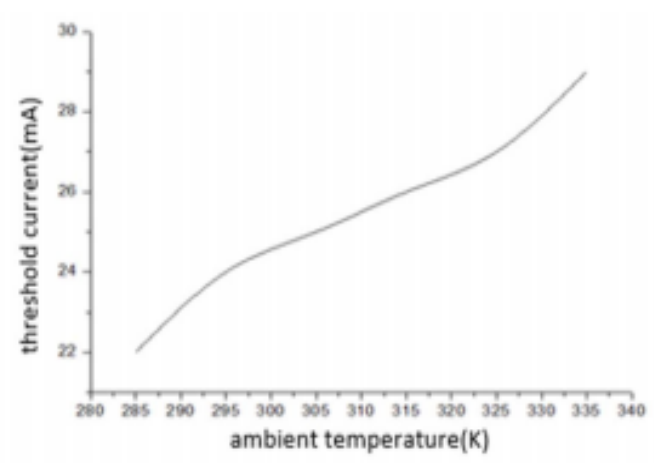

Figure 4. Threshold current curve with the ambient temperature 
It can be seen from the figure, as the encompassing temperature changes, the edge current was essentially higher and optical yield power is significantly reduced.

\section{CONCLUSION}

This paper for the most part influencing the warm attributes of the semiconductor laser and the surrounding temperature of the laser to do a preparatory review, utilizing ANSYS limited component investigation programming, joined with the warm qualities of the semiconductor laser hypothesis, broke down the test display gotten by the encompassing temperature influence the execution of the semiconductor laser relationship.

1. To begin with subtle elements on the effect of the adjustment in temperature of the semiconductor laser would influence limit present and differential quantum productivity, yield optical power, which can be induced that that at the typical temperature extend, the temperature rises, significantly affect these parameters, in basic terms, the temperature rise will lessen the execution of the laser.

2. Utilizing ANSYS recreation comes about on the encompassing temperature of the interior temperature of the laser, which could be inferred that as the surrounding temperature changes, changes in the inner temperature of the laser chip is as corresponding relations, natural temperature, the temperature inside the laser It will take after the ascent.

3. This two conclusions can be joined as take after, under ordinary encompassing temperature go, as the surrounding temperature rising, the limit current of the semiconductor laser builds, the outer differential quantum effectiveness is diminished, the optical yield power is lessened, and the yield wavelength side long, the slant proficiency abatements, soundness and administration life have declined.

\section{REFERENCES}

[1] Xia. Influence of external cavity length on lasing wavelength variation of fiber grating semiconductor laser with ambient temperature. Optik-International Journal for Light and Electron Optics. 2003; 114(6).

[2] Qing C. The problem with beam quality for semiconductor laser. Optik-International Journal for Light and Electron Optics. 2016; 127(8): 3701-3702.

[3] Zhang. An optical non-contact measurement method for hot-state size of cylindrical shell forging. 2012.

[4] Senthilkumar K, Kalaivani T, Kanagesan S, Balasubramanian V. Low temperature method for synthesis of ZnS quantum dots and its luminescence characterization studies. Appl Surf Sci. 2013; 264: 17-20.

[5] Senthilkumar K, Kalaivani T, Kanagesan S, Balasubramanin V. Low temperature method for synthesis of starchcapped ZnSe nanoparticles and its characterization studies. Journal of Applied Physics. 2012; 112(11): 114-331.

[6] Soomro DM, Chong SC, Memon ZA, Abbasi F. Power Quality Improvement in QUCEST Larkana Campus by Using Three Types of Power Filters. International Journal of Power Electronics and Drive Systems (IJPEDS). 2017; 8(4).

[7] Bin Mohd Saad WH, Wuen KC, bin Mat Ibrahim M, Saad NH, Radz SB, bin Mohamad Shokri AS, bin Karis MS. Study on the Effect of the Ambient Temperature toward the Quality of Sleep. International Journal of Electrical and Computer Engineering (IJECE). 2017; 7(6).

[8] Najeeb M, Mansor M, Feyad H, Taha E, Abdullah G. An Optimal LFC in Two-area Power Systems using a Metaheuristic Optimization Algorithm. International Journal of Electrical and Computer Engineering (IJECE). 2017 Dec 1;7(6).

[9] Rajalakshmi C, ArGunasekaran IK. Low-power high-speed amplification using filterbank for digital hearing aids. International Journal of MC square Scientific Research (IJMSR). 2016; 8(1): 60-73. 